\section{Cureus}

\title{
Ruptured Intracranial Dermoid Cyst: Unusually Rapid Disease Course Leading to a Fatal Outcome
}

\author{
Muhammad Furqan ${ }^{1}$, Akintunde R. Akinleye ${ }^{2}$, Pavan Mahendra. Ravella ${ }^{3}$ \\ 1. Department of Medicine-Oncology Section, New York Medical College 2. Department of Hematology \\ and Oncology, Westchester Medical Center 3. Westchester Medical Center
}

$\square$ Corresponding author: Muhammad Furqan, drfurqandow@gmail.com Disclosures can be found in Additional Information at the end of the article

\section{Abstract}

Ruptured intracranial dermoid cyst (RICDC) is rare and its clinical presentation varies widely from case to case. Principles of its management are derived from experience of managing small numbers of patients. It was considered fatal disease decades ago, but as understanding improves, in most cases, it was found to be a non-fatal pathology anymore. Our patient was a young female who had a short duration of worsening headache with no other alarming features because of RICDC that eventually caused her death. It is extremely rare for a RICDC to have such a rapid disease course and leading to a fatal outcome. Our case will increase the spectrum of presentation and complications of RICDC in the existing literature that may potentially affect the decision-making process for these patients.

Categories: Neurosurgery

Keywords: dermoid, cyst, intracranial, ruptured, tumor

\section{Introduction}

Intracranial dermoid cysts are rare, non-neoplastic, congenital ectodermal inclusion cysts of embryological origin containing various ectodermal derivatives, including apocrine glands, sebaceous glands, hairs, squamous epithelium, and occasionally teeth [1-5]. Epidermoid cysts, in contrast, only have squamous epithelial lining. Intracranial dermoid cysts are commonly located in the suprasellar, frontobasal and temporobasal regions [1-5]. Spontaneous rupture of these cysts is uncommon, and so far, fewer than one hundred cases have been reported in the medical literature [1-3]. Ruptured intracranial dermoid cysts (RICDC) can present with headache (33\%), seizures (26\%), cerebral ischemia with focal deficit (16\%), and aseptic meningitis (8\%) [1-5]. It can also lead to death [6-7].

Received 03/27/2013 Review began 03/28/2013 Published 05/16/2013

\section{C) Copyright 2013}

Furqan et al. This is an open access article distributed under the terms of the Creative Commons Attribution License CC-BY 3.0., which permits unrestricted use, distribution, and reproduction in any medium, provided the original author and source are credited.

\section{Case Presentation}

A 22-year-old female with history of chronic headaches presented to the emergency room (ER) with an episode of moderately severe headache. After assessment, her symptoms were presumed secondary to frontal sinusitis, and she was sent home with prescriptions of a decongestant and an analgesic. Headache severity was partially alleviated for couple of days, and she again presented with worsening headache without any associated symptoms of fever, nausea/vomiting, neck stiffness, focal deficit, or altered sensorium. A CT scan of the head revealed a suprasellar fat-containing mass with scattered fat densities in the brain (Figure 1, Panel A). She was given narcotics for the headache and advised to be admitted for further inpatient management. However, she refused and signed out against the medical advice from 


\section{Cureus}

the ER. The next morning she was brought in by ambulance after being found unresponsive at home. She was intubated and had no motor or eye response. Other than worsening headache, her significant other did not report any other associated symptoms before she became comatose. Upon arrival to the ER, she was clinically brain dead. MRI (T1 weighted images) revealed a $3 \mathrm{~cm}$ hyperintense lesion in the suprasellar cistern with spread of fatty material in subarachnoid space with lepto-meningeal enhancement (Figure 1, Panel B). No intervention was done, and brain death was confirmed by flow scan. Her organs were harvested for transplantation. Autopsy of her brain revealed ruptured sub-hypophyseal dermoid cyst with aseptic meningitis (Figure 1, Panels $\mathrm{C}$ and D).
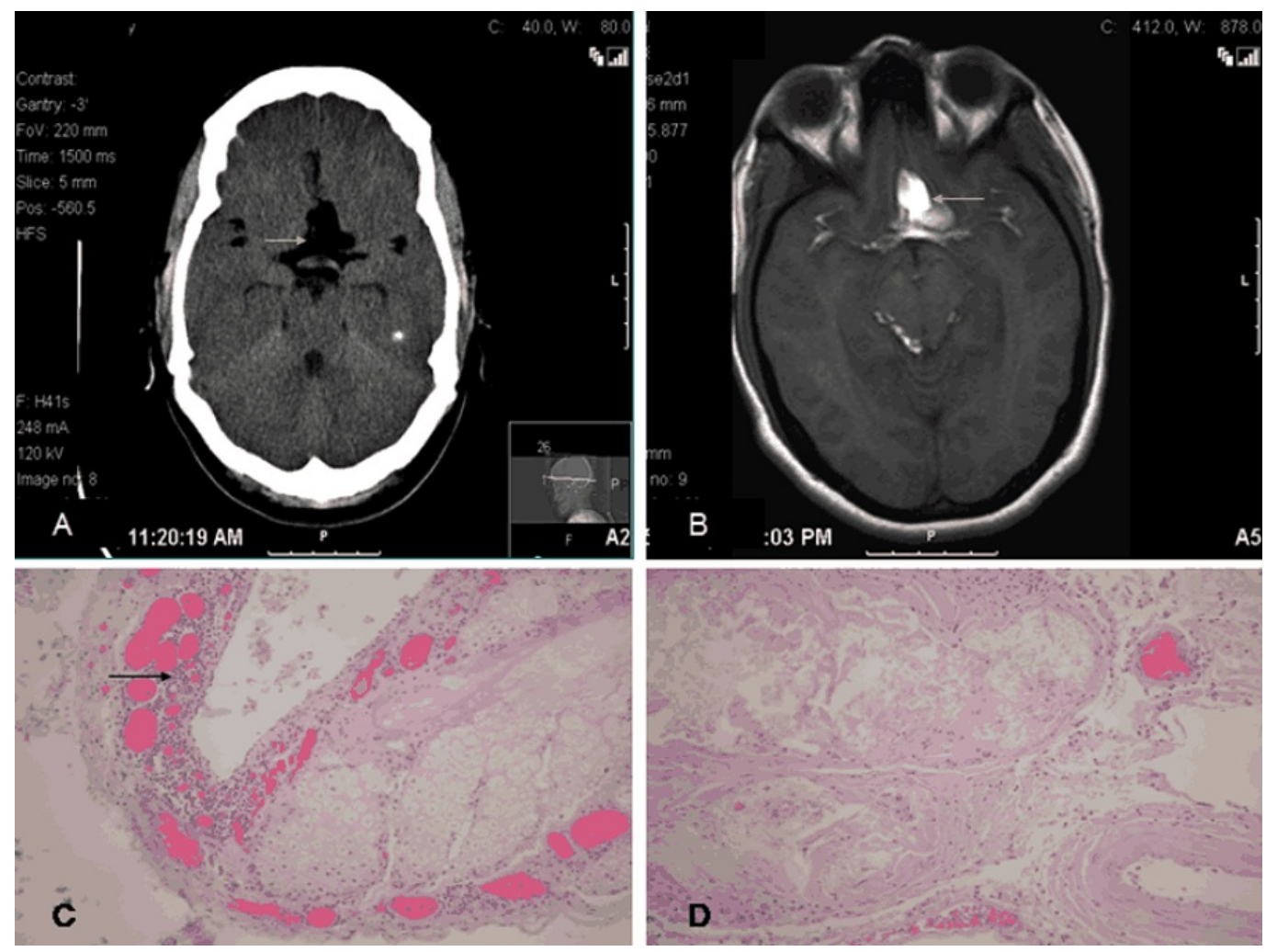

\section{FIGURE 1: Ruptured intracranial dermoid cyst}

Ruptured intracranial dermoid cyst: Panel A: CT scan - Sub-hypophyseal hypodense lesion. Panel B: MRI (T1-weighted image) Sub-hypophyseal hyperintense lesion. Panel C: Histopathology of the wall of dermoid cyst (H\&E staining) depicting sebaceous secretions, glands and inflammatory cells (arrow). Panel D: Showing inflammatory reaction secondary to ruptured dermoid tumor in surrounding meningeal tissues.

\section{Discussion}

Intracranial dermoid cysts comprise $0.04 \%$ - $0.6 \%$ of all intracranial tumors [3]. They derive from inclusion of ectodermally-committed cells at the time of neural groove closure in embryonic life, whereas teratomas contain tissues from all the primitive germ layers [5]. Dermoid cysts are composed of a thick fibrous capsule lined by stratified squamous epithelium enclosing a thick, viscous, greenish-brown fluid, a mix of lipids, cholesterol crystals, hairs, and decomposed epithelial cells $[3,5]$. They increase in size with accumulation of glandular secretions and desquamated cells from the lining epithelium. They are extra-axial, located in basilar region near the midline. Symptoms associated with unruptured cysts are usually due to mass effect and slowly progressive in nature, while rupture results in spillage of fatty globules 
into the ventricles and/or in subarachnoid space. The irritative effect of these lipid metabolites leads to aseptic granulomatous meningitis, vasospasm with or without cerebral ischemia, and hydrocephalus [1-5]. Rupture of these cysts is often a spontaneous process, but closed head injury has been implicated in certain cases [1- 3, 5, 8-10].

Because of the excess fat content, they possess characteristic appearance on various imaging studies. Internal content of these lesions appear as fat density (negative Hounsfield units) on head CT without any contrast enhancement, except for the capsule which occasionally can have partial enhancement. They appear hyperintense on T1 weighted MR images. Unruptured cysts appear heterogeneous on $\mathrm{T} 2$ weighted images, whereas dispersed droplets appear hyperintense from a ruptured cyst. If the internal fat content is relatively low, the lesion will reveal cerebrospinal fluid-like signal intensity. In such cases, fluid attenuation inversion recovery (FLAIR) is useful, in that the fat will appear hyperintense (bright) on a background of suppressed fluid signal (dark). If meningitis is present, meningeal enhancement is evident after administration of gadolinium contrast $[2-4,11]$.

Most patients are diagnosed during an evaluation of various neurological manifestations or severe unexplained headaches $[1-5,8,12-15]$, but rarely it can present as an incidental finding [9-10]. However, our patient only had a subacute onset of worsening headache with no associated symptoms; nonetheless, her condition deteriorated rapidly, resulting in a fatal outcome within days which is very unusual course for this disease entity. Though RICDC can be fatal, such outcomes were seen only in the remote past because of the significant delay in a correct diagnosis and surgical intervention as evidenced by the reports of Becker [6] and Manlapaz [7]. Review of recent literature suggests that ruptured dermoid cysts are usually nonfatal and well-tolerated, even after rupture [1-3, 5].

Early surgical removal is indicated for symptomatic, unruptured cysts; however, if they have already ruptured, there is no clear consensus as to how quickly they should be removed. Rapid intervention should be attempted in patients having neurological deficit [2-4, 16]. Liu, et al. [2] suggested that patients with small asymptomatic lesions or if headache is the only symptom, close observation with serial imaging can be a reasonable management option.

\section{Conclusions}

Patients with new onset or worsening headaches should be assessed thoroughly. Ruptured dermoid cysts are rare and their presentation varies with differing disease course. They potentially carry the risk of death if not managed in a timely fashion. Patients should be informed about all possible complications and risks before selecting any management strategy at any particular point during the course of disease.

\section{Additional Information}

\section{Disclosures}

Human subjects: Consent was obtained by all participants in this study. Conflicts of interest: In compliance with the ICMJE uniform disclosure form, all authors declare the following: Payment/services info: All authors have declared that no financial support was received from any organization for the submitted work. Financial relationships: All authors have declared that they have no financial relationships at present or within the previous three years with any organizations that might have an interest in the submitted work. Other relationships: All authors have declared that there are no other relationships or activities that could appear to have influenced the submitted work.

\section{References}


1. El-Bahy K, Kotb A, Galal A, El-Hakim A: Ruptured intracranial dermoid cysts. Acta Neurochir (Wien). 2006, 148:457-462.

2. Liu JK, Gottfried ON, Salzman KL, Schmidt RH, Couldwell WT: Ruptured intracranial dermoid cysts: Clinical, radiographic and surgical features. Neurosurgery. 2008, 62: 377-384.

3. Orakcioglu B, Halatsch ME, Fortunati M, Unterbert A, Yonekawa Y: Intracranial dermoid cysts: Variations of radiological and clinical features. Acta Neurochir. 2008, 150(12): 1227-34.

4. Ray MJ, Barnett DW, Snipes GJ, Layton KF, Opatowsky MJ: Ruptured intracranial dermoid cyst . Proc Bayl Univ Med Cent. 2012, 25(1):23-5.

5. Stendel R, Pietila TA, Lehmann K, Kurth R, Suess O, Brock M: Ruptured intracranial dermoid cysts. Surg Neurol. 2002, 57:391-398.

6. Becker WJ, Watters GV, De-Chadarevian JP, Vanasse M: Recurrent aseptic meningitis secondary to intracranial epidermoids. Can J Neurol Sci. 1984, 11:387-389.

7. Manlapaz JS: Ruptured intracranial dermoid. Report of a case and survey of previously reported cases. Am J Surg. 1960, 100:723-730.

8. Das CJ, Tahir M, Debnath J, Pangtey GS: Ruptured intracranial dermoid. J. Neurol Neurosurg Psychiatry. 2007, 78:624-625.

9. Funke M: Ruptured intracranial dermoid as an incidental finding. Aktuelle Radiol . 1995, 5: 232-4.

10. Ptak T: CT pitfalls in emergency radiology: A chronically ruptured intracranial dermoid tumor mimicking pneumocephalus in an acute multi-trauma evaluation. Emerg Radiol. 2007, 16:453-456.

11. Kucera JN, Roy P, Murtagh R: Ruptured intracranial dermoid cyst manifesting as new onset seizure: A case report. J Radiol Case Rep. 2011, 5(4):10-8.

12. Amendola MA, Garfinkle WB, Ostrum BJ, Katz MR, Katz RI: Preoperative diagnosis of a ruptured intracranial dermoid cyst by computerized tomography. Case report. J Neurosurg. 1978, 48:1035-7.

13. Johnson DG, Stemper SJ, Withers TK: Ruptured "giant" supratentorial dermoid cyst . Journal of Clinical Neuroscience. 2005, 12(2):198-201.

14. Oursin C, Wetzel SG. Lyrer P, Bachili H, Stock KW: Ruptured intracranial dermoid cyst. J Neurosurg Sci . 1999, 43(3):217-20.

15. Smith AS, Benson JE, Blaser SI, Mizushima A, Tarr RW, Bellow EM: Diagnosis of ruptured intracranial dermoid cyst: Value of MR over CT. Am J Neuroradiol . 1991, 12:175-80.

16. Lunardi P, Missori P: Suppratentorial dermoid cysts. J Neurosurg. 1991, 75(2):262-6. 